\title{
Sustainable Enterprise Excellence: Towards a framework for holistic data-analytics
}

\author{
Rick L. Edgeman, Professor of Sustainability \& Performance \\ Interdisciplinary Center for Organizational Architecture \& AU-Herning \\ Aarhus University, Denmark \\ Email: RLEDGE@ASB.DK or Edgeman Rick@yahoo.com
}

\section{Structured Abstract}

Purpose: Sustainable Enterprise Excellence (SEE) is defined and developed through integration and expansion of business excellence modeling and sustainability thought. The intent is to enable simple yet reliable enterprise assessment of triple bottom line (TBL) performance and produce actionable enterprise foresight that can enable next best practices and sources of sustainable competitive advantage through innovation.

Methodology: Key elements of SEE are identified from various business excellence and sustainability reporting sources, including the Global Reporting Initiative, the UN Global Compact 10 Principles, and criteria of the European Quality Award and America's Baldrige National Quality Award. From these a model and key criteria are distilled, maturity scales developed, and a simple means of assessment presented.

Findings: A compact model and supporting maturity assessment approach similar in structure to those behind established excellence awards are developed that enable enterprise assessment of progress toward SEE. The resulting assessment is delivered in a highly consumable, combined narrative and graphic format referred to as a SEE NEWS Report.

Practical Implications: The assessment approach presented enables both enterprise progress toward Sustainable Enterprise Excellence and enterprise-to-enterprise comparability. Foresight provided by the assessment enables further advancement.

Social Implications: The social and environmental dimensions of SEE imply that enterprises progressing with respect to its model will of necessity positively contribute to the social fabric.

Originality: Sustainable Enterprise Excellence as superior TBL performance resulting from integration of ethical, effective and efficient governance with triple top line strategy is developed, together with a means of maturity assessment.

Keywords: Governance, Innovation for Sustainability, Maturity Assessment, Performance Dashboard, Resilience, Sustainable Enterprise Excellence, Sustainable Innovation, SWOT Plot Narrative, Triple Bottom Line Performance, Triple Top Line Strategy.

Article Classification: Research paper

Corporate Governance - The International Journal of Business in Society, Vol. 13, No. 5, pp. pending - 2013

Special Issue on Sustainability \& Innovation: Accepted 20 June 2013 


\section{Sustainable Enterprise Excellence: Towards a framework for holistic data-analytics}

\section{INTRODUCTION}

Organizations seek strategic resilience and robustness, "the ability to dynamically reinvent business models and strategies as the operating environment changes, to continuously anticipate and adjust to changes that threaten their core earning power, and to change before the need to change becomes desperately obvious" (Hamel and Välikangas, 2003). Resilience is the ability of an enterprise to recover from negative, often unanticipated shocks to its ecosystem where the degree to which an organization is resilient varies along a spectrum. Organizational robustness is not ability to recover from such shocks, but resistance or immunity to their impact. Resilience and robustness are neither identical nor of necessity fully compatible: the set of strategies and actions maximizing resiliency may differ from the strategies and actions maximizing robustness. Whenever such differences exist, an organization should exercise care to elaborate and make informed and intelligent choices among tradeoffs between resiliency, robustness and other factors so that any choice of strategies, actions, and organization design is constrained.

Environmental and social contexts establish enterprise boundary conditions or constraints that are influenced by competitive, legal and regulatory contexts. Firm-level strategy and governance that jointly optimize resilience and robustness must also regard sustainability. In turn these promote sustainable superior performance across the environmental, societal, and economic sustainability dimensions of the triple bottom line (Elkington, 1997) or TBL. Sustainability is a business imperative (Lubin and Esty, 2010) that stimulates enterprise innovation strategies and tactics (Nidumolu et al., 2009) capable of providing the next big source of competitive advantage (Laszlo and Zhexembayeva, 2011). This chain is component to Sustainable Enterprise Excellence (SEE) and originates in the external social and enterprise context, providing impetus for firm social-ecological innovation (Edgeman and Eskildsen, 2014) that largely targets external constituents. Mild refinement of the definition of SEE provided by Edgeman and Eskildsen (2013) yields:

Sustainable Enterprise Excellence balances the complementary and competing interests of key stakeholder segments, including society and the natural environment and increases the likelihood of superior and sustainable competitive positioning and hence long-term enterprise success that is defined by high-level organizational resilience and robustness and by continuously relevant and responsible governance, strategy and actions that produce superior results.

This is accomplished through organizational design and function that emphasize innovation, enterprise intelligence \& analytics, operational, supply chain, customer-related, human capital, financial, marketplace, societal, and environmental performance. Sustainable Enterprise Excellence integrates ethical, efficient and effective (E3) enterprise governance with $3 E$ (equity, ecology, economy) Triple Top Line strategy throughout enterprise culture and activities to produce Triple Bottom Line 3P (people, planet, profit) results that are simultaneously pragmatic and innovative and that provide foresight suggestive of next best practices and sources of competitive advantage.

Special Issue on Sustainability \& Innovation: Accepted 20 June 2013 
Alternative formulations of "SEE" include the macroeconomic concept of a "sustainable enterprise economy" (Waddock and McIntosh, 2011), and "social, economic, and environmental / ecological" - an alternate TBL expression. Irrespective of the specific SEE formulation, governance is critical (Elkington, 2006).

\section{DECONSTRUCTING SUSTAINABLE ENTERPRISE EXCELLENCE}

\section{Relationships to Business Excellence, Enterprise Intelligence \& Analytics, and Foresight}

Business / Enterprise Excellence (BEE) models derive from total quality management (TQM) theory and practice. The BE models supporting America's Baldrige National Quality Award and the European Quality Award are globally dominant. Effective implementation of BEE models and strategies correlates positively with improved performance in emphasized model areas (Balasubramanian et al., 2005). Inclusion of intelligence and analytics in SEE is driven by rapid evolution of data-driven decision-making toward vastly more complex and computationally-intensive "big data analytics" (LaVelle et al., 2011) that support sophisticated transformation and translation of information into actionable enterprise intelligence and foresight.

Emphasis of big data intelligence and analytics is among several distinctions between SEE and BEE that should not be ignored - not because they provide failsafe evaluation of all important organizational issues and decisions - but because of the rapidly increasing volume of information generated from which intelligence and foresight that account for complex interactions of factors must be gleaned, and for which data confidentiality and security must be assured. Social-ecological factors are often incorporated into enterprise evaluations to improve performance through generation and implementation of strategic foresight (Petrini and Pozzebon, 2009). Such use of intelligence and analytics offers improved solutions to complex enterprise challenges, including marketplace, supply chain navigation, and societal and ecological oriented ones, and hence progress toward SEE.

Intelligence and analytics are acknowledged organization design components (Atkinson et al., 2000; Galbraith, 2012) that enable pursuit of continuously relevant and responsible performance - an effort further aided by appropriate organizational structure. Continuous relevance suggests that iterative generation and implementation of enterprise foresight is of elevated importance. Such foresight should provide three main perspectives relative to TBL performance: the strategist perspective that elaborates new business fields where SEEdriven innovation may occur; the initiator perspective that increases the number of SEEdriven innovation ideas and concepts; and the oppositional perspective that challenges SEEdriven innovation projects to enhance their performance (Rohrbeck and Germünden, 2011).

\section{Governance \& Strategy}

Inclusion of sustainability in enterprise strategy and governance is now common practice (Fowler and Hope, 2007). Corporate governance is vital to both corporate sustainability (Aras and Crowther, 2008) and organizational resilience (Avery and Bergsteiner, 2011), especially in high intensity enterprise environments marked by the need to integrate and govern complex human capital and technological interfaces (Smith et al., 2005). Ethical and transparent enterprise governance will at minimum embrace the Ten Principles of the United Nations Global Compact (UNGC) that address human rights, labor, ecological, and 
anti-corruption issues (Adams and Petrella, 2010) that are echoed and added to by the GRI or Global Reporting Initiative (Rasche and Gilbert, 2012). Other context-specific ethical elements will almost certainly impact organizational governance practices - for example the business sectors or activities in which an organization engages may dictate adherence to particular formal codes of conduct.

BEE models consider senior-level organizational leadership that defines, refines, and deploys enterprise mission, vision and strategy in order to fulfill organizational objectives and continuously improve performance in areas of competitive importance, including enterprise innovation and agility (Bou-Llusar et al., 2009). In contrast, SEE stresses ethical, effective, efficient and transparent strategy and governance as causal to enterprise performance of all sorts. SEE thus focuses on integration of E3 governance with 3E Triple Top Line (TTL) strategy (McDonough and Braungart, 2002a) emphasizing social equity, ecological responsibility, and economic soundness along with innovation, resilience and robustness. Enterprise governance emphasizing eco-efficiency is positively correlated with operational and supply chain robustness as well as to value differential that increases over time between more and less eco-efficient enterprises (Guenster et al., 2010).

\section{SEE Connections: Governance, Innovation, Resilience \& Robustness}

TQM and BEE practice and more rapid innovation are strongly linked (Sun and Zhao, 2010; Teece, 2010) yet curiously, BEE models have not explicitly attended to innovation's role in BEE and assessment of its impact on BEE progress. Careful and explicit consideration and assessment of innovation in SEE differentiates SEE from BEE and, while effectively implemented ecologically and socially responsible enterprise governance and strategy has been positively associated with enterprise value (Al-Najjar and Anfimiadou, 2012; Jo and Harjoto, 2011), it is the combination of such governance and strategy with innovation capability and capacity that most strongly drives enterprise value (Hart and Dowell, 2011).

Innovation is also critical to important SEE co-products: enterprise resilience and robustness. It has been documented that enterprises with the greatest diversity in their innovation strategies portfolio are also the most resilient ones (Reinmoeller and van Baardwijk, 2005) with four key innovation strategies being knowledge management, exploration, cooperation, and entrepreneurship. Knowledge management is reuse of tacit and explicit enterprise knowledge, exploration addresses experimentation aimed at finding meaningful re-combinations of enterprise knowledge, cooperation stresses assessing and reusing complementary knowledge of supply chain and other enterprise ecosystem partners, and entrepreneurship refers to experimentation aimed at identification of new meaning in the enterprise landscape.

Innovation has documented positive impact on environmental and social performance and is inextricably connected to sustainability (Melville, 2010; Terjesen et al., 2011), while management innovation has deep impact on enterprise governance (Birkinshaw and Mol, 2006). Hoffman (2012) provides a means of deeply embedding customer needs in design of sustainability-oriented products while Edgeman and Eskildsen (2012) provide a means of integrating societal and environmental considerations into the innovation process.

Attention to organizational resilience and robustness further distinguishes SEE from BEE and organizations more advanced with respect to SEE are generally more resilient and robust. More innovative enterprises are also less susceptible than less innovative 
enterprises, and hence also more robust and more resilient in the face of sectoral and environmental pressures (Gunday et al., 2011).

From the perspective of enterprise intelligence and analytics, organizations with greater technological and market intelligence absorptive capacity are better able to navigate competitive turbulence and are hence more robust (Lichtenthaler, 2009). This is critical to innovation, assimilation and transfer of intelligence, and subsequent mobilization of resources that contribute to improved performance across an array of key enterprise performance dimensions, including innovation and leverage of social capital across the enterprise supply chain and its broader ecosystem (Maurer et al., 2011).

\section{Social-Ecological Innovation}

Innovation plays a pivotal role in a Sustainable Enterprise Excellence and is prominently featured in the Springboard to SEE model that is later presented. Specifically, SEE emphasizes social-ecological innovation (SEI) resulting from strategic integration of sustainable innovation and innovation for sustainability. Sustainable innovation manifests in enterprise cultures characterized by rigorous, regular, systematic, and systemic innovation throughout the enterprise and is central to its strategy, financial performance, and other key performance domains (Wolpert, 2002). Innovation for sustainability implies - especially - that innovation is intentionally sensitive to and both positively and tangibly impacts the enterprise's societal or ecological performance. SEI, thus manifests in organizations with a sustainable innovation culture where a significant subset of the organization's innovation portfolio focuses on societal and ecological sustainability.

This SEI formulation suggests that biomimetic innovation inspired by designs and principles occurring in nature (Benyus, 2002) and innovation incorporating cradle-to-cradle design principles (McDonough and Braungart, 2002b) that posit organizations can have positive, restorative impacts on the natural environment and society, with output of one process supplying "energy" to another, might be particularly applicable in SEE-driven organizations. SEI thus contributes to large-scale social-ecological resilience (Olsson and Galaz, 2011) by elevating the capacity of a social-ecological system to confront challenges, adapt, and continue to develop (Wüstenhagen et al., 2008).

Eskildsen and Edgeman (2012) describe SEI as "lean, green, ethical and real", offer 10R (basic) and 10A (advanced) strategies that advance SEI, and provide criteria against which SEI maturity may be measured. They assert that SEI contributes to enterprise value creation through: revenue growth; cost, risk and waste reductions; strategic redesign of products, processes or business functions; and differentiation of the enterprise value proposition.

\section{SEE MODELING, MATURITY, AND ASSESSMENT}

The Springboard to SEE model is intended to yield actionable feedback and foresight that enable derivation and implementation of next best (SEE and other) practices and sources of sustainable competitive advantage. The Springboard deeply embeds innovation, enterprise intelligence and analytics, and human capital, and is overt in its integration of E3 Governance with 3E Strategy to yield 3P performance. While prior development makes innovation and enterprise intelligence and analytics obvious choices for emphasis, the case for the centrality of human capital is fundamentally driven by the propensity for human capital to serve as a barrier to or enabler of corporate social responsibility (CSR), 
sustainability (CS), and other performance (Garavan et al., 2010). The intense nexus between CSR and CS (Montiel, 2008), coupled with diversifying innovation strategies through human capital is a hallmark of highly resilient enterprises (Reinmoeller and van Baardwijk, 2005). Other elements of SEE, including financial performance, operational performance, and marketplace performance are well-documented contributors to or outcomes of BEE with well-established means of assessment. SEE incorporates these, while also emphasizing ecological and societal performance, SEI, foresight, and organizational resilience and robustness.

SEE regards resilience, robustness, societal performance, ecological performance, and other performance as highly intentional co-products of enabling SEE strategies and processes such as ones related to innovation and enterprise intelligence and analytics. Enabling processes are critical components of any reasonable SEE model that must be assessed for maturity relative to specified criteria. Such models and criteria are non-prescriptive and identify traits and trajectories (relative maturity) of assessed areas in high-level narrative and qualitative terms, but do not elaborate how performance in assessed areas should be accomplished, leaving such context-sensitive specifics to the enterprise.

Springboard use demands development and application of a companion maturity assessment and reporting regime composed of criteria and associated maturity scales. Springboard maturity scales and assessment criteria are simple to apply, but too extensive to include herein. The assessment report employs dashboard analytics (Eckerson, 2011) formed from a composite of NEWS Compasses coalesced into a NEWS Compass Dashboard and SWOT Plot Narratives collected into a SWOT Plot Dashboard, that together yield an overall Springboard to SEE NEWS Report. Although SEI is addressed in the Springboard and by its assessment regime, more comprehensive SEI assessment may be pursued by using the combined 10A and 10R assessment approach of Eskildsen and Edgeman (2012).

\section{Springboard Modeling \& Assessment}

The Springboard to SEE addresses elements cited in the SEE definition and highlighted in discussion to this juncture. This is accomplished via integration, elaboration, and significant expansion of the models, foundational principles, and concepts of dominant BEE models, the UNGC 10 Principles, the Global Reporting Initiative, cradle-to-cradle design principles, and more.

The Springboard is positioned at a complexity level designed to make it accessible and useful to organizations ranging from novice to sophisticate in their excellence and sustainability expertise, while rendering feedback and foresight that are insightful and actionable. The Springboard Model displayed in Figures 1 and 2 is reminiscent of the Baldrige and European Quality Award models. The model of Figure 2 will be explained from left-to-right by first examining the coarse, high-level view of Figure 1.

Special Issue on Sustainability \& Innovation: Accepted 20 June 2013 


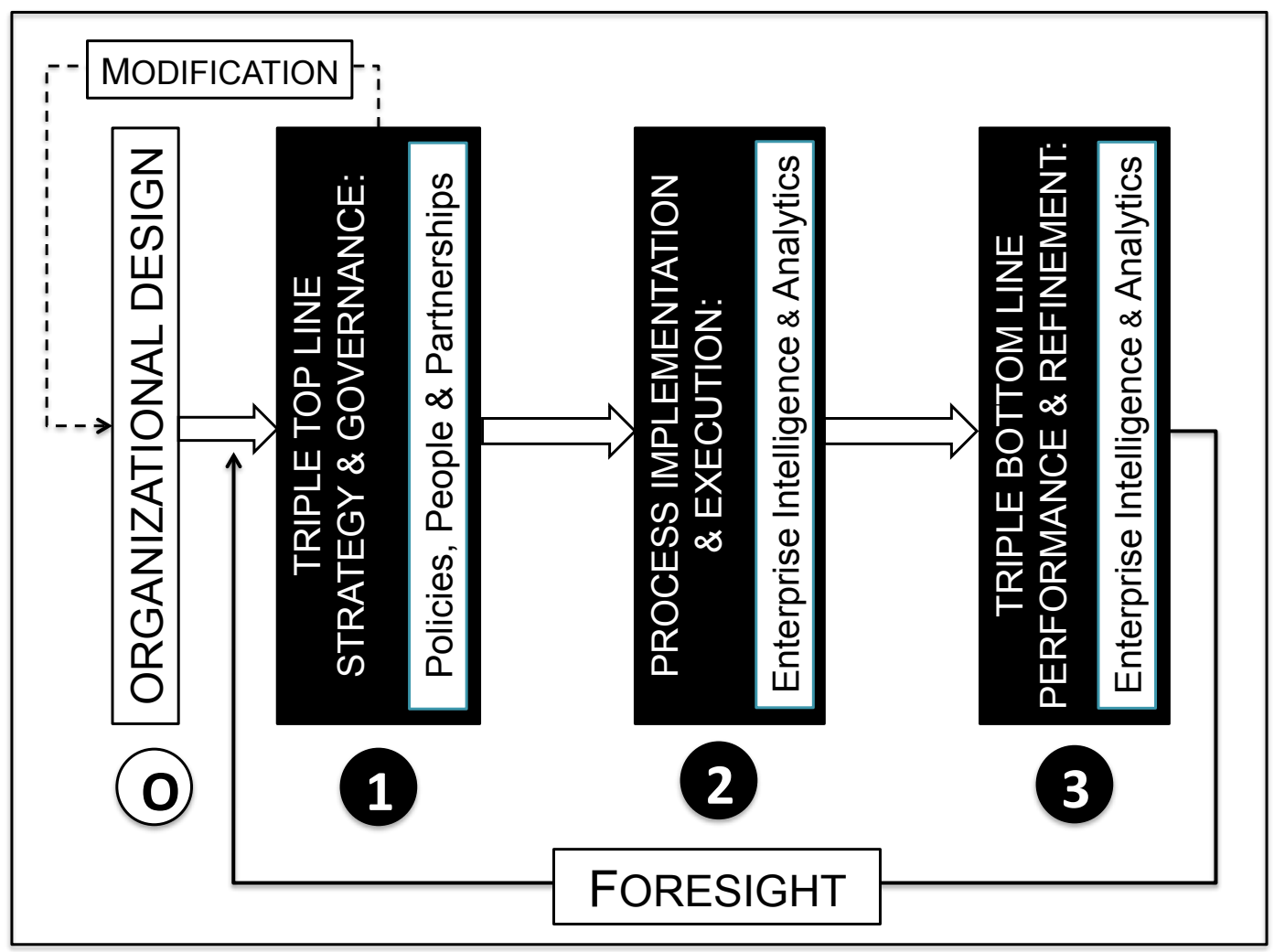

Figure 1. Springboard to SEE High-Level View

In Figure 1, an enterprise is constrained by "initial enterprise conditions" of its design (0). Whatever its design, the enterprise must be governed and strategy must be formed and transacted with transactional media including policies, people and partnerships (1) subsequently implemented and executed in the form of processes that, in combination with enterprise intelligence and analytics (2) lead to performance in areas of importance to the enterprise (3) that in turn yield foresight that informs the next strategy cycle. In some cases embedding foresight in strategy leads to modifications in organization design. Given this description of Figure 1, Figure 2 may now be explained.

Segment (1) of Figure 2 concentrates on integration of "Triple Top Line 3E Strategy \& E3 Governance", focusing especially on the four elements portrayed, beginning with transparent and responsible governance that emphasizes sustainability, resiliency and robustness. Similarly there is explicit consideration of the gathering, absorption, and generation and use of new enterprise intelligence, with ethical regard for data confidentiality and security. Careful analysis of intelligence yields carefully formed innovation and change strategy, including potential organization design change, in ways that increase enterprise agility - a key element of resilience and robustness.

The middle segment of Figure 2 addresses implementation and execution of processes that aim to accomplish strategy. Primary organizational processes of interest in SEE include generation and analysis of enterprise intelligence, particularly as these relate to continuous improvement, innovation, sustainability, resilience and robustness. These drive human capital processes that include competence-building and acquisition to create a more agile 
human capital composite via increased skills, knowledge, and practice and hence increased flexibility of an enterprise's individual members. Much of this competence will be directed toward enterprise innovation, including SEI.

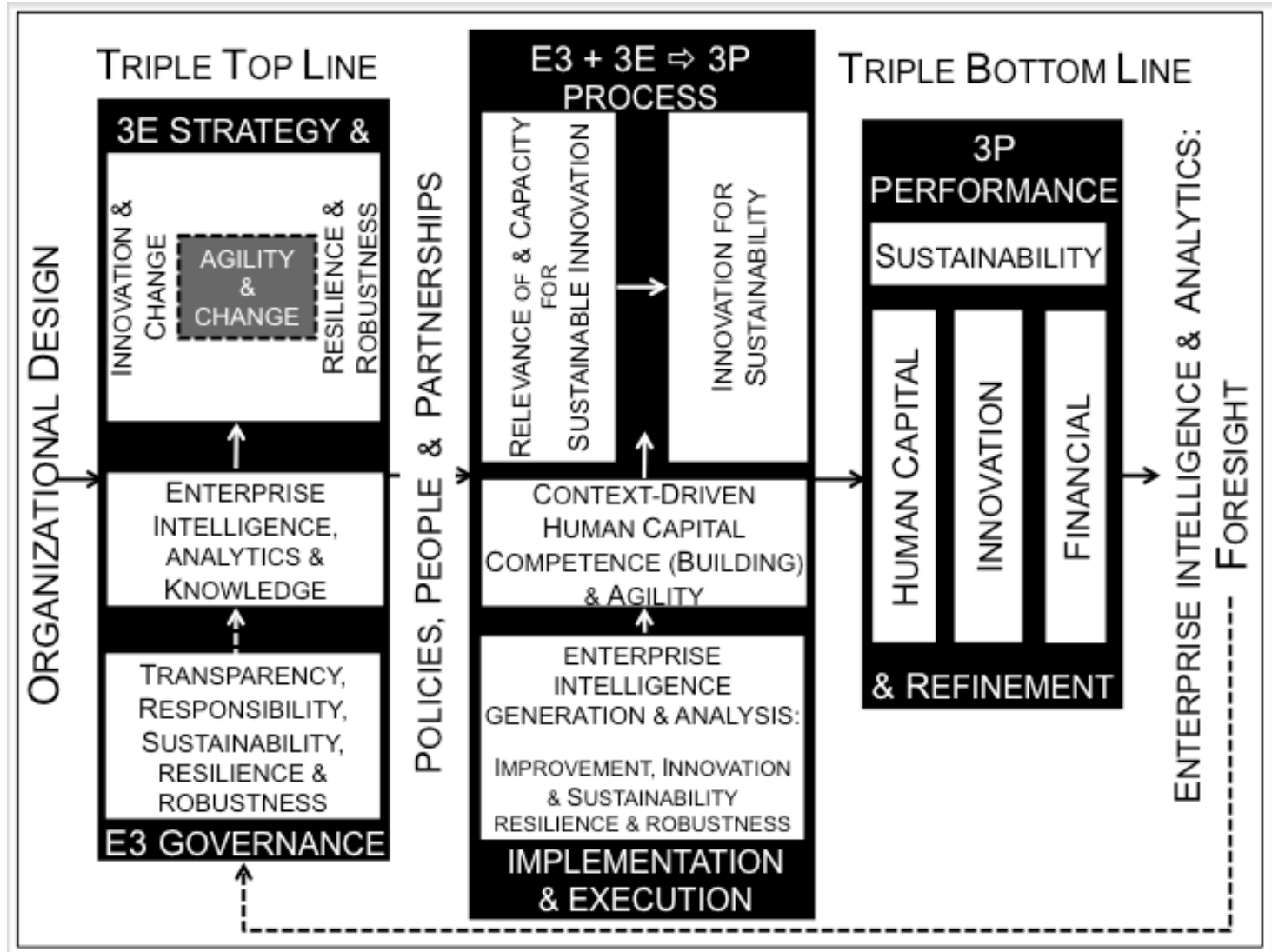

Figure 2. Springboard to Sustainable Enterprise Excellence Model: Detailed View

Segment (3) of Figure 2 addresses whether the strategy of segment (1) and processes of segment (2) deliver "TBL Performance and Refinement" in four critical areas: financial, innovation, human capital, and sustainability performance. The extraction and analysis of performance-based intelligence from these and other context-specific areas generate feedback and foresight that may be incorporated immediately to improve performance or that may inform the next strategy cycle. This insinuates that feedback and foresight should be both actionable and directional in that identifiable actions needed should be accompanied by clear aims and objectives, including ones with overt innovation, resilience, robustness and sustainability implications.

\section{Springboard Criteria and Maturity Assessment}

Irrespective of enterprise competitive landscape and innovation culture, SEE assessment demands development and use of assessable criteria focused on areas relevant to advancing the enterprise toward SEE. As previously noted, many possible assessment areas exist, with the criteria recorded in Table 1 representing a synthesis and referred to as "compass dimensions". 
Table 1. Springboard to SEE NEWS Compass Point Elements

\section{NEWS POINTS COMPASS DIMENSIONS}

\section{STRATEGY \& GOVERNANCE COMPASS (1)}

\begin{tabular}{|c|c|}
\hline \\
\hline $\mathbf{N}$ & Transparency, Responsibility, Sustainability, Resilience \& Robustness \\
\hline $\mathbf{E}$ & Enterprise Intelligence, Analytics \& Knowledge \\
\hline $\mathbf{W}$ & Organizational Design: Innovation \& Design, Resilience \& Robustness \\
\hline \multirow[t]{2}{*}{$\mathbf{S}$} & Organizational Design: Agility \& Change \\
\hline & PROCESS IMPLEMENTATION \& EXECUTION COMPASS (2) \\
\hline $\mathbf{N}$ & $\begin{array}{l}\text { Enterprise Intelligence Generation \& Analysis: Improvement, Innovation } \\
\text { \& Sustainability, Resilience \& Robustness }\end{array}$ \\
\hline $\mathbf{E}$ & Context Specific Human Capital Competence Building \& Agility \\
\hline $\mathbf{W}$ & Relevance \& Capacity for Sustainable Innovation \\
\hline \multirow[t]{2}{*}{$\mathbf{S}$} & Innovation for Sustainability \\
\hline & FINANCIAL PERFORMANCE RESULTS COMPASS (3) \\
\hline $\mathbf{N}$ & Sustainability Investment \& Return \\
\hline $\mathbf{E}$ & Supply / Value Chain \& Other Performance Improvement \\
\hline $\mathbf{W}$ & Human Capital Investment \& Return \\
\hline \multirow[t]{2}{*}{$\mathbf{S}$} & R\&D: Return on \& Reinvestment in Innovation \\
\hline & SUSTAINABILITY PERFORMANCE RESULTS COMPASS (4) \\
\hline $\mathbf{N}$ & Non-Financial Results \& Refinement Traceable to Sustainability \\
\hline $\mathbf{E}$ & Environmental Results \& Refinement Traceable to Sustainability Efforts \\
\hline $\mathbf{W}$ & $\begin{array}{l}\text { Human Capital \& Other Results and Refinement Traceable to } \\
\text { Sustainability }\end{array}$ \\
\hline \multirow[t]{2}{*}{$\mathbf{S}$} & Societal Sustainability Results \& Refinement \\
\hline & INNOVATION PERFORMANCE RESULTS COMPASS (5) \\
\hline $\mathbf{N}$ & Innovation for Sustainability: Society and the Environment \\
\hline $\mathbf{E}$ & $\begin{array}{l}\text { Innovation for Resilience \& Robustness \& Other Context Specific } \\
\text { Innovation }\end{array}$ \\
\hline $\mathbf{W}$ & Business Model \& Organization Design Innovation \\
\hline \multirow[t]{2}{*}{$\mathbf{S}$} & Sustainable Innovation \\
\hline & HUMAN CAPITAL PERFORMANCE RESULTS COMPASS (6) \\
\hline $\mathbf{N}$ & Innovation Capacity \& Performance \\
\hline $\mathbf{E}$ & Specific \& General Competence \& Agility \\
\hline $\mathbf{W}$ & Strategic \& Tactical Continuous Improvement \\
\hline $\mathbf{S}$ & Sustainability Intelligence \& Performance: Society and the Environment \\
\hline
\end{tabular}

Enterprise maturity relative to criteria should be based on sound maturity indices or scales (Porter and Tanner, 2012). While maturity scales have been developed for all assessed Springboard areas, presentation and discussion of these scales is outside the scope of the present paper. While all scales employ 0-to-10 integer assessment, with division of these values into five descriptive/narrative categories, the precise narratives for which are highly specific to each assessed area, the generic characterizations of these five categories are in each instance "very low maturity" (0-1), "low maturity" (2-3), "moderate maturity" (4-6), "high maturity" (7-8), and "very high maturity" and (9-10). 


\section{The SEE NEWS Report: Compasses, SWOT Plot Narratives, and Dashboards}

Springboard NEWS Compasses derive their name from the fact that four criteria have been developed for each of six primary assessment areas represented by "Triple Top Line 3E Strategy \& E3 Governance" (Figure 1, Segment 1), "Process Implementation \& Execution" (Figure 1, Segment 2), and the "financial performance", "innovation performance", "human capital performance", and "sustainability performance" elements of the "Triple Bottom Line 3P Performance and Refinement" block provided in Figure 1, Segment 3. Assessment results are intended to "point the direction forward" for the enterprise, hence the "Compass" terminology with the four criteria of each assessed area represented by easily recalled "North-East-West-South" or NEWS results that provide a combination of feedback and foresight or "news", hence use of the term NEWS Compass.

There are thus six compasses associated with the Springboard of Figures 1 and 2, results from which may be combined into a "super compass" with six axes, of which each axis is associated with one of the six initial NEWS Compasses. The value plotted on a given axis of the super compass results from consolidation of the N-E-W-S maturity ratings of the associated NEWS Compass. Assessment is done using the specific 0-through-10 maturity scales cited previously and combining the seven compasses yields a dashboard similar to the one portrayed in Figure 3.

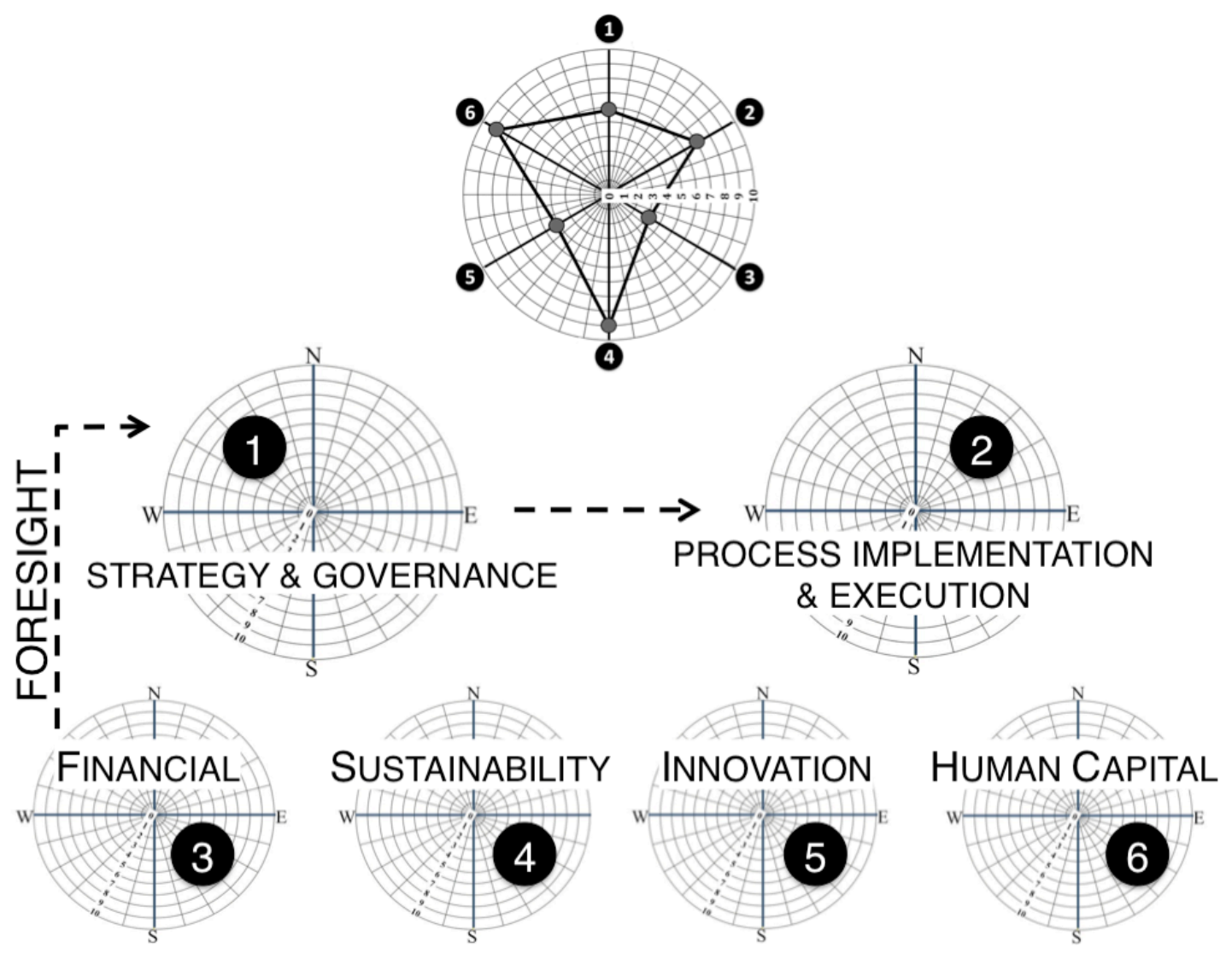

Figure 3. Springboard to SEE NEWS Compass Dashboard 
While the maturity on a given performance dimensional axis is assessed on a 0 -to-10 scale, relative valuation of the axes of any given compass, and of the compasses themselves, should be driven by enterprise context: its competitive landscape including both its present and desired international positioning and its specific, potentially unique considerations of social, ethical, environmental, and human capital elements that are only tangentially addressed by frameworks such as ones the Baldrige and European Quality Awards employ. The ability to deliver customized assessment is particularly useful to organizations operating internationally, or ones with an array of operationally and competitively distinct divisions.

To formalize these ideas, represent the four N-E-W-S maturity values for the Ith $^{\text {th }}$ compass of Table 1 by and the respective weights assigned to these by $\mathrm{W}_{\mathrm{NI}}, \mathrm{W}_{\mathrm{EI}}, \mathrm{W}_{\mathrm{WI}}, \mathrm{W}_{\mathrm{SI}}$, where

$$
0 \leq \mathrm{W}_{\mathrm{JI}} \leq 1,\left(\mathrm{~W}_{\mathrm{NI}}+\mathrm{W}_{\mathrm{EI}}+\mathrm{W}_{\mathrm{WI}}+\mathrm{W}_{\mathrm{SI}}=1\right) \text {, and } 0 \leq \mathrm{M}_{\mathrm{NI}}, \mathrm{M}_{\mathrm{EI}}, \mathrm{M}_{\mathrm{WI}}, \mathrm{M}_{\mathrm{SI}} \leq 10
$$

for $\mathrm{J}=\mathrm{N}, \mathrm{E}, \mathrm{W}, \mathrm{S}$ and $\mathrm{I}=1,2, \ldots, 6$ for compasses 1 through 6 of Table 1 . Similarly, the single summary value for NEWS Compass I, $\mathrm{V}_{\mathrm{I}}$, plotted on the "super compass" becomes:

$$
\mathrm{V}_{\mathrm{I}}=\mathrm{W}_{\mathrm{NI}} \mathrm{M}_{\mathrm{NI}}+\mathrm{W}_{\mathrm{EI}} \mathrm{M}_{\mathrm{EI}}+\mathrm{W}_{\mathrm{WI}} \mathrm{M}_{\mathrm{WI}}+\mathrm{W}_{\mathrm{SI}} \mathrm{M}_{\mathrm{SI}}
$$

As with individual maturity ratings, $M$, the nature of $V$ is such that $0 \leq V \leq 10$, with the caveat that - unlike $\mathrm{M}$ - non-integer values of $\mathrm{V}$ are possible.

These formulations of $\mathrm{W}$ and $\mathrm{V}$ acknowledge circumstances specific to enterprise context where dimensions and compasses may not be of equal importance, including ones where a dimension may be contextually irrelevant and assigned a zero weight. To illustrate, the arithmetic mean will assign equal weight $(0.25)$ to each N-E-W-S dimension for the various compasses of Table 1, but another selection of weights that more precisely mirrors organizational context and that is consistent with the above formulation might be preferred.

Possible, but perhaps not preferable unless all other valuations are retained, is a singlevalue maturity assessment, $S$, of firm-level SEE performance that weights the six compasses of Table 1 with weights $\mathrm{C}_{1}, \mathrm{C}_{2}, \ldots, \mathrm{C}_{6}$. That is

$$
\mathrm{S}=\mathrm{C}_{1} \mathrm{~V}_{1}+\mathrm{C}_{2} \mathrm{~V}_{2}+\ldots+\mathrm{C}_{6} \mathrm{~V}_{6} \text { where } 0 \leq \mathrm{C}_{\mathrm{I}} \leq 1 \text { and }\left(\mathrm{C}_{1}+\mathrm{C}_{2}+\ldots+\mathrm{C}_{6}=1\right)
$$

Each NEWS Compass is associated with a companion SWOT Plot Narrative addressing Strengths-Weaknesses-Opportunities-Threats for the assessed area where strengths and weaknesses represent factors internal to the enterprise and its ecosystem, whereas both opportunities and threats represent enterprise externalities. Figure 4 portrays a generic SWOT Plot Narrative where the questions in each block may be customized according to the assessed area and enterprise competitive context. Similar to the compasses, SWOT Plot Narratives may be assembled into a second dashboard. The comprehensive SEE assessment called the Springboard to SEE News Report results from coalescence of the two dashboards. 


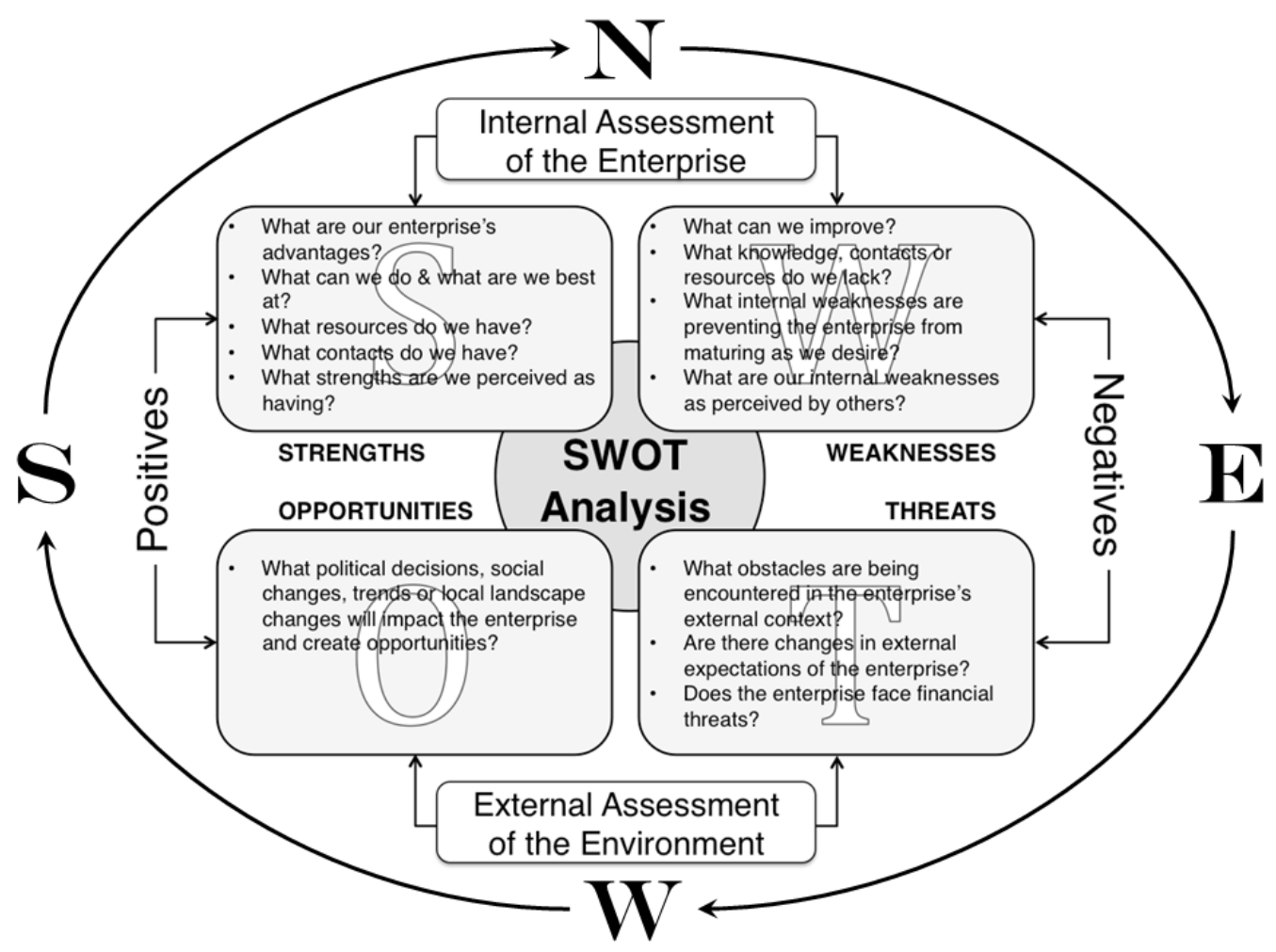

Figure 4. Springboard to SEE SWOT Plot Narrative Dashboard

Springboard assessment is a relatively simple approach to modeling firm performance based on key performance indicators. Various alternative approaches exist, including use of the oft-mentioned assessment regimes behind the Baldrige and European Quality Awards, GRI assessment, balanced scorecard frameworks (Kaplan and Norton, 1992), CSR-oriented Communications of Progress associated with the UNGC 10 Principles, and dashboard approaches such as the TESCO Strategy Steering Wheel (Cummings and Angwin, 2011) or those used to assess social-ecological innovation performance (Edgeman and Eskildsen, 2014).

\section{FUTURE RESEARCH DIRECTIONS \& CONCLUSIONS}

The sustainability megatrend exerts substantial influence on organizational contexts in and conditions to which their form, function, and prosperity are subject. The Sustainable Enterprise Excellence (SEE) concept stems from the merger of business excellence and sustainability, and is fundamentally concerned with aiding organizations in what is most certainly an asymptotic quest to become and remain continuously relevant, responsible, economically viable, and economically successful. In all SEE aims to integrate socially equitable, ecologically attuned, and economically sound triple top line strategy with ethical, effective and efficient enterprise governance to produce superior societal (people) and human capital, environmental (planet), and financial (profit) performance. Many paths toward such superior performance exist, with proven radical improvement approaches such the highly systematic and analytics-driven product, process and system innovation and design ones offered by six sigma (Edgeman, 2013) appearing particularly promising. 
Relevance and responsibility foremost concern the key triple bottom line sustainability elements of ecological and societal performance, whereas economic performance underscores the importance of primary BEE components such as operational, supply chain, customer, human capital, and market performance that map to the financial aspect of the triple bottom line. Whereas BEE regards enterprise leadership as essential, the marriage of sustainability and business excellence suggests that it is not leadership per se that SEE should emphasize, but the larger concept of governance that subsumes leadership. Similarly, there is an irreversible trend toward the criticality of big data analytic capability so that rather than the "data-driven decision-making" approach traditionally associated with business excellence, SEE focuses on more computationally intensive data and information generation, collection, extraction, and interpretive procedures that - when added to traditional data-driven methods - yields the area of SEE referred to as enterprise intelligence and analytics.

Other key areas of emphasis in SEE that are either absent from, or under-emphasized in $\mathrm{BEE}$ and/or sustainability modeling are environmental performance, societal performance, enterprise resilience, enterprise robustness, and innovation. Resilience and robustness are not directly addressed in SEE, but instead seen as intentional byproducts or co-products.

Sustainable Enterprise Excellence is a rapidly evolving construct and, like the models, criteria, and assessment regimens associated with leading BEE models it is expected that the Springboard to Sustainable Enterprise Excellence should and will evolve as macro-level business, societal, and environmental contexts merit. In particular it can be anticipated that much work will be done regarding the roles of enterprise intelligence and analytics, enterprise resilience and robustness, governance for sustainability, and the criticality and centrality of innovation to SEE.

The Springboard to SEE provides a first among many possible models of Sustainable Enterprise Excellence. Similarly, the Springboard NEWS Compasses, companion SWOT Plot Narratives, corresponding dashboards, and Springboard to SEE NEWS Report provide one approach to SEE performance assessment. In all, the intention of these is that they should deliver performance feedback and actionable foresight that result in identification and implementation of next best practices capable of further advancing SEE performance.

As Sustainable Enterprise Excellence is explored more deeply, elaborated in greater detail, its criteria honed, assessed areas and their maturity become better understood, and intelligence and analytical methods are strengthened, measurement will be sharpened and become both more relevant and time-sensitive. These enable enterprises in nearer to realtime to become more rapidly responsive and more proactive with respect to changing competitive landscapes. Equally, it can be anticipated that qualitative, inherently softer analytics may be developed and sharpened, using such approaches as qualitative comparative analysis and fuzzy set logic (Ragin and Sedziaka, 2013) to deliver artfully crafted maturity scales with results that may be added to the suggested SEE NEWS Dashboard as one or more additional compasses.

Apart from obvious enhancement in organizational SEE assessment capacity and capability, natural implications of heightened enterprise intelligence and analytics include improvements in enterprise resilience and robustness. These should in turn yield better strategic direction regarding enterprise innovation targets and activities that are also strongly influenced by the many faces of societal, environmental, and competitive stress. 
But what about the relationships between and relative balance of enterprise and external factors: how should these be approached to better address resilience and robustness considerations?

Enterprises are composed of people and exist for the purpose of producing results that benefit their often myriad stakeholders: what of the organizations' human capital? Innovation is critical to SEE and how can enterprise human capital talent and skills be enriched and optimized to drive innovation. Similarly, how can better engagement be cultivated between the enterprise and the people for whom the organization innovates, including direct users of its innovations, to yield more fruitful co-creation (Edgeman and Eskildsen, 2012; Hoffmann, 2012)?

Such are only a few of the many issues and challenges that reside at the heart of competitive advantage and of becoming a continuously relevant and responsible enterprise. Advancement of SEE performance will largely rely on the degree of success with which these issues and challenges are addressed.

\section{REFERENCES}

Adams, C. and Petrella, L. (2010), "Collaboration, connections and change: the UN Global Compact, the Global Reporting Initiative, Principles for Responsible Management Education and the Globally Responsible Leadership Initiative", Sustainability Accounting, Management and Policy Journal, Vol. 1 No. 2, pp. 292-296.

Al-Najjar B, Anfimiadou A. (2012), "Environmental policies and firm value", Business Strategy and the Environment, Vol. 21 No. 1, pp. 49-59.

Aras, G. and Crowther, D. (2008), "Governance and sustainability: an investigation into the relationship between corporate governance and corporate sustainability", Management Decision, Vol. 46 No. 3, pp. 433-448.

Atkinson, S., Schaefer, A. and Viney, H. (2000), "Organizational structure and effective environmental management", Business Strategy and the Environment, Vol. 9 No. 2, pp. 108121.

Avery, G.C. and Bersteiner, H. (2011), "Sustainable leadership practices for enhancing business resilience and performance”, Strategy \& Leadership, Vol. 39 No. 3, pp. 5-15.

Balasubramanian S, Mathur I, Thakur R. 2005. "The impact of high-quality firm achievements on shareholder value: focus on Malcolm Baldrige and J.D. Power and Associates awards", Journal of the Academy of Marketing Science, Vol. 33 No. 4, pp. 413-422.

Benyus, J. (2002), Biomimicry: Innovation Inspired by Nature, HarperCollins, New York, NY.

Birkinshaw, J. and Mol, M. (2006), "How management innovation happens", MIT Sloan Management Review, Vol. 47 No. 4, pp. 81-88.

Bou-Llusar, J.C., Escrig-Tena, A.B., Roca-Puig, V. and Beltran-Martin, I. (2009), “An empirical assessment of the EFQM excellence model: Evaluation as a TQM framework relative to the MBNQA model”, Journal of Operations Management, Vol. 27 No. 6, pp. 1-22.

Corporate Governance - The International Journal of Business in Society, Vol. 13, No. 5, pp. pending - 2013

Special Issue on Sustainability \& Innovation: Accepted 20 June 2013 
Cummings, S. and Angwin, D. (2011), "Stratography: The art of conceptualizing and communicating strategy, Business Horizons, Vol. 54, No. 5, pp. 435-446.

Eckerson, W. (2011), Performance Dashboards: Measuring, Monitoring and Managing Your Business, $2 e$, John Wiley \& Sons, Inc., Hoboken, NJ.

Edgeman, R. (2013), "Six sigma enablement of sustainable enterprise excellence \& resilience", Six Sigma Forum, in press.

Edgeman, R. and Eskildsen, J. (2012), "The C4 model of people-centered innovation: culture, consciousness, and customer-centric co-creation", Journal of Innovation and Best Business Practice , Vol. 2012: 14 pages. DOI: 10.5151/2012.932564

Edgeman, R. and Eskildsen, J. (2013), "Modeling and assessing sustainable enterprise excellence”, Business Strategy and the Environment, DOI: 10.1002/bse.1779.

Edgeman, R. and Eskildsen, J. (2014), "Social-ecological innovation", in Wang, J. (Ed.), Encyclopedia of Business Analytics and Optimization, IGI Global, Hershey, PA, in press.

Elkington J. (1997), Cannibals with Forks: The Triple Bottom Line of 21 ${ }^{\text {st }}$ Century Business, Capstone Publishing, Oxford, UK.

Elkington, J. (2006), “Governance for sustainability”, Corporate Governance, Vol. 14, No. 6, pp. 522-529.

Eskildsen, J. and Edgeman, R. (2012), “Continuous relevance \& responsibility: integration of sustainability \& excellence via innovation”, Journal of Positive Management, Vol. 3 No. 1, pp. 67-81.

Fowler, S.J. and Hope, C. (2007), "Incorporating sustainable business practices into company strategy”, Business Strategy and the Environment, Vol. 16 No. 1, pp. 26-38.

Galbraith, J.R. (2012), "The future of organization design", Journal of Organization Design, Vo. 1 No. 1, pp. 3-6.

Garavan, T.N., Heraty, N., Rock, A. and Dalton, E. (2010), “Conceptualizing the behavioral barriers to CSR and CS in organizations: a typology of HRD interventions", Advances in Developing Human Resources, Vol. 12 No. 5, pp. 587-613.

Guenster, N., Bauer, R., Derwall, J. and Koedijk, K. (2010), “The economic value of corporate eco-efficiency", European Financial Management, Vol. 17 No. 4, pp. 679-704.

Gunday, G., Ulusoy, G., Kilic, K. and Alpkan, L. (2011), "Effects of innovation types on firm performance”, International Journal of Production Economics, Vol. 133 No. 2, pp. 662-676.

Hamel, G. and Välikangas, L. (2003), "The quest for resilience”, Harvard Business Review, Vol. 81 No. 9, pp. 52-64.

Hart, S.L. and Dowell, G. (2011). "A natural-resource-based view of the firm: fifteen years 
later", Journal of Management, Vol. 37 No. 5, pp. 1464-1479.

Hoffmann. E. (2012), User Integration in Sustainable Product Development: Organisational Learning Through Boundary-Spanning Processes, Greenleaf Publishing, Sheffield, UK.

Jo, H. and Harjoto, M.A. (2011), "Corporate governance and firm value: the impact of corporate social responsibility", Journal of Business Ethics, Vol. 103 No. 3, pp. 351-383.

Kaplan, R. and Norton, D. (1992), "The balanced scorecard: measures that drive performance", Harvard Business Review, Vol. 70 No. 1, pp. 71-79.

Laszlo, C. and Zhexembayeva, N. (2011), Embedded Sustainability: the Next Big Competitive Advantage, Greenleaf Publishing, Sheffield, UK.

LaVelle, R., Lesser, E., Shockley, R., Hopkins, M.S. and Kruschwitz, N. (2011), "Big data, analytics, and the path from insights to value", MIT Sloan Management Review, Vol. 52 No. 2, pp. 21-31.

Lichtenthaler, U. (2009), "Absorptive capacity, environmental turbulence, and the complementarity of organizational learning processes", Academy of Management Journal, Vol. 52 No. 4, pp. 822-846.

Lubin, D. and Esty, D. (2010), "The sustainability imperative”, Harvard Business Review Vol. 88 No. 5, pp. $42-50$.

Maurer, I., Bartsch, V. and Ebers, M. (2011), "The value of intra-organizational social capital: how it fosters knowledge transfer, innovation performance, and growth", Organization Studies, Vol. 32 No. 2, pp. 157-185.

McDonough, W, \& Braungart M. (2002a). Design for the triple top line: New tools for sustainable commerce. Corporate Environmental Strategy, Vol. 9 No. 6, pp. 251-258.

McDonough, W. and Braungart, M. (2002b), Cradle to Cradle: Remaking the Way We Make Things. North Point Press, New York, NY.

Melville, N.P. (2010), "Information systems innovation for environmental sustainability", MIS Quarterly, Vol. 34 No. 1, pp. 1-21.

Montiel, I. (2008), “Corporate social responsibility and corporate sustainability: separate pasts, common futures”, Organization \& Environment, Vol. 21 No. 3, pp. 245-269.

Nidumolu, R., Prahalad C.K., and Rangaswami, M.R. (2009), "Why sustainability is now the key driver of innovation”, Harvard Business Review, September, pp. 57-64.

Olsson, P. and Galaz, V. (2011), "Social-ecological innovation and transformation", in Nicholls, A. and Murdoch, A. (Eds.), Social Innovation: Blurring Boundaries to Reconfigure Markets, Palgrave MacMillan, London, UK, pp. 223-247. 
Petrini, M. and Pozzebon, M. (2009), "Managing sustainability with the support of business intelligence: integrating socio-environmental indicators and organizational context", The Journal of Strategic Information Systems, Vol. 18 No. 4, pp. 178-191.

Porter, L. and Tanner, S. (2012), Assessing Business Excellence, 2e, Elsevier ButterworthHeinemann, Oxford, UK.

Ragin, C.C. and Sedziaka, A.A. (2013), "QCA and fuzzy set applications to social movement research", in Snow, D.A., Porta, D.D., and Klandermans, B. (Eds.), The Wiley-Blackwell Encyclopedia of Social and Political Movements, DOI: 10.1002/9780470674871.wbespm482.

Rasche, A. and Gilbert, D.U. (2012), "Institutionalizing global governance: the role of the United Nations Global Compact", Business Ethics: A European Review, Vol. 21 No. 1, pp. 100114.

Reinmoeller, P. and Van Baardwijk, N. (2005), "The link between diversity and resilience", MIT Sloan Management Review, Vol. 46 No. 4, pp. 61-65.

Rohrbeck, R. and Gemünden, H.G. (2011), “Corporate foresight: its three roles in enhancing the innovation capacity of a firm", Technological Forecasting and Social Change, Vol. 78 No. 2, pp. 231-243.

Smith, A., Stirling, A. and Berkhout, F. (2005), "The governance of sustainable sociotechnical transitions", Research Policy, Vol. 34 No. 10, pp. 1491-1510.

Sun, H. and Zhao, Y. (2010), "The empirical relationship between quality management and the speed of new product development", Total Quality Management \& Business Excellence, Vol. 21 No. 4, pp. 351-361.

Tari, J.J. and Molina-Azorin, J.F. (2010), "Integration of quality management and environmental management systems: similarities and the role of the EFQM Model", The TQM Journal, Vol. 22 No. 6, pp. 687-701.

Teece D.J. (2010), "Business models, business strategy and innovation", Long Range Planning Vol. 43 No. 2-3, pp. 172-194.

Terjesen, S., Patel, P.C. and Covin, J.G. (2011), "Alliance diversity, environmental context and the value of manufacturing capabilities among new high technology ventures", Journal of Operations Management, Vol. 29 No. 1-2, pp. 105-115.

Waddock, S. and McIntosh, M. (2011), SEE Change: Making the Transition to a Sustainable Enterprise Economy, Greenleaf Publishing, Sheffield, UK.

Wolpert, J.D. (2002), "Breaking out of the innovation box", Harvard Business Review, Vol. 80 No. 8, pp. 76-83.

Wüstenhagen, R., Hamschmidt, J., Sharma, S. and Starik, M. (Eds.) (2008), Sustainable Innovation and Entrepreneurship: New Perspectives in Research on Corporate Sustainability, Edward Elgar, Cheltenham, UK. 